\title{
안면마비 환자에서 표면 근전도 검사와 통상적 근전도 검사간 상관관계
}

\author{
장하늘 ${ }^{1}$, 유승돈 ${ }^{2}$, 이종하 $^{1}$, 소윤수 ${ }^{1}$, 김동환 $^{2}$, 전진만 $^{1}$, 이승아 $^{2}$, 김희상 ${ }^{1}$, 윤동환 $^{1}$, 권정호 $^{1}$ \\ ${ }^{1}$ 경희의료원 재활의학과, ${ }^{2}$ 강동경희대학교병원 재활의학과
}

\section{Correlation between Surface Electromyography and Conventional Electromyography in Facial Nerve Palsy}

\author{
Haneul Jang ${ }^{1}$, Seung Don Yoo ${ }^{2}$, Jong Ha Lee ${ }^{1}$, Yunsoo Soh¹, Dong Hwan Kim², \\ Jinmann Chon ${ }^{1}$, Seung Ah Lee ${ }^{2}$, Hee-Sang Kim ${ }^{1}$, Dong Hwan Yun ${ }^{1}$, Jung Ho Kwon ${ }^{1}$ \\ 1 Department of Physical Medicine \& Rehabilitation, KyungHee University Medical Center, \\ ${ }^{2}$ Department of Physical Medicine \& Rehabilitation, Kyung Hee University Hospital at Gangdong, Seoul, Korea
}

\begin{abstract}
Objective: To assess the correlation between surface electromyography (SEMG) and conventional EMG in patients with facial nerve palsy. Additionally, compare the discomfort and the time required by the patients in two methods.

Method: 36 patients with facial palsy were given nerve conduction studies (NCS) via conventional EMG. Then, the peak root mean square (RMS) values were obtained from the SEMG. We also recorded visual analogue scale (VAS), HouseBrackmann scale, and the time required for the examination.

Results: Pearson's correlation coefficient between the amplitude loss ratio of the RMS values obtained by SEMG compared to the unaffected side (RSEMG) and the amplitude loss ratio of CMAP amplitudes compared to the unaffected side (RCMAP) was 0.567 at the frontalis, 0.456 at the orbicularis oculi, 0.393 at the nasalis, and 0.437 at the orbicularis oris. An increase in RSEMG is positively correlated with an increase in RCMAP. The mean VAS score with conventional EMG was $3.55 \pm 1.42$, whereas that experienced when using SEMG was $0.11 \pm 0.52$ and the mean time required for conventional EMG was $610 \pm 103.84$ seconds, while that required for SEMG was $420 \pm 86.32$ seconds.

Conclusion: This study demonstrated a significant positive correlation between facial muscle activities as measured by SEMG and conventional EMG in patients with facial nerve palsy. SEMG has the benefits of being more comfortable and faster when diagnosing facial palsy.
\end{abstract}

Key Words: electromyography, facial paralysis, surface electromyography

Received April 9, 2018

Introduction

Revised (1st) May 16, 2018, (2nd) July 5, 2018

Accepted September 4, 2018

Corresponding Author: Jung Ho Kwon

Department of Physical Medicine \& Rehabilitation, KyungHee University

Medical Center, 23 Kyungheedae-ro, Dongdaemun-gu, Seoul 02447,

Korea

Tel: 82-2-958-8114, Fax: 82-2-958-8113, E-mail: kjhlad@naver.com

Copyright $\odot$ by Korean Association of EMG

Electrodiagnostic Medicine
This is an Open Access article distributed under the terms of the Creative Commons Attribution Non-Commercial License (http://creativecommons.org/licenses/by-nc/4.0) which permits unrestricted non-commercial use, distribution, and reproduction in any medium, provided the original work is properly cited. 
The incidence of peripheral facial nerve paralysis is estimated to be 20 35/100,000. ${ }^{1}$ Peripheral facial paresis is caused by metabolic, inflammatory, or traumatic events. $^{2,3}$ The diagnosis of facial nerve paresis takes into account clinical examinations, patient medical history, and electrophysiological evaluations including electromyography (EMG) and examination of the blink reflex. ${ }^{4,5}$ To determine the prognosis, it is important to compare the quantitative side-to-side compound muscle action potentials (CMAPs). ${ }^{6}$ EMG measures muscle activity by detecting and amplifying the CMAP that are generated by muscle fibers when they contract. However, a clinical nerve conduction study (NCS) is associated with pain that is evoked when electrical impulses propagate to the nerve.

Surface electromyography (SEMG) is a means of recording muscle action potentials using electrodes placed on the surface of the skin over the target muscles. SEMG is a non-invasive procedure involving the detection, recording, and interpretation of the electrical activity of muscles. ${ }^{7,8}$ Some studies have measured muscle activity in various muscles with SEMG rather than conventional EMG, and they produced meaningful results. $^{7-16}$ In a previous study, SEMG may be useful in the diagnosis of facial paresis. ${ }^{17}$ Currently, conventional EMG is commonly used to diagnose facial paresis. However, there has been no study comparing SEMG and conventional EMG in facial nerve palsy patients. The purpose of this study is 1) to find out the degree of correlation between SEMG and conventional EMG results, and 2) to uncover the possibility for clinical application when SEMG is used to study facial nerve palsy patients.

\section{Materials and Methods}

\section{1) Subjects}

We prospectively studied patients who presented with acute peripheral facial palsy at a single center (Department of Physical Medicine and Rehabilitation, OO University Medical Center, Korea) between March
2016 and February 2017. Written informed consent was obtained from all subjects prior to the study. Patients with central facial palsy, congenital palsy, and patients with surgical reconstruction of the facial nerve were excluded. Demographic and clinical information was obtained from review of the patients' medical histories.

\section{2) Clinical evaluation of facial nerve function}

The initial facial nerve function was evaluated clinically using the House-Brackmann (HB) facial nerve grading system. The HB grading system judges facial function in six categories (grade I = normal function in all facial areas, grade II = mild dysfunction, grade III = moderate dysfunction, grade IV = moderately severe dysfunction, grade $\mathrm{V}$ = severe dysfunction, and grade VI = complete paralysis plus gross asymmetry at rest).

\section{3) Equipment}

The REF SX230 1000 system (Biometrics Ltd., Newport, United Kingdom) was used to obtain root mean square (RMS) data for SEMG. The EMG signals were recorded at a sampling rate of $1,000 \mathrm{~Hz}$, and filtered with a bandwidth of 20 460 Hz. Input impedance was > 10,000,000 M Ohms and the common mode rejection ratio $(60 \mathrm{~Hz} \mathrm{~dB})$ was greater than $96 \mathrm{~dB}$. Each electrode was connected to a portable data acquisition unit, DataLOG (Biometrics Ltd., Newport, United Kingdom). The data was analyzed by Biometrics Analysis software version 8.51 .

\section{4) Conventional EMG evaluation}

The first electrodiagnostic test including NCS and EMG was performed. For stimulation and recording, a Medelec-Synergy system (Oxford Instruments Plc., Abingdon, United Kingdom) was used. Before the test, patients were trained about facial muscle movement. The positions of the electrodes were determined by means of topographic-anatomical landmarks as well as origin and insertion points of the muscles (Fig. 1). NCS was performed first on the healthy side and then repeated on the affected side. A bipolar stimulator was 

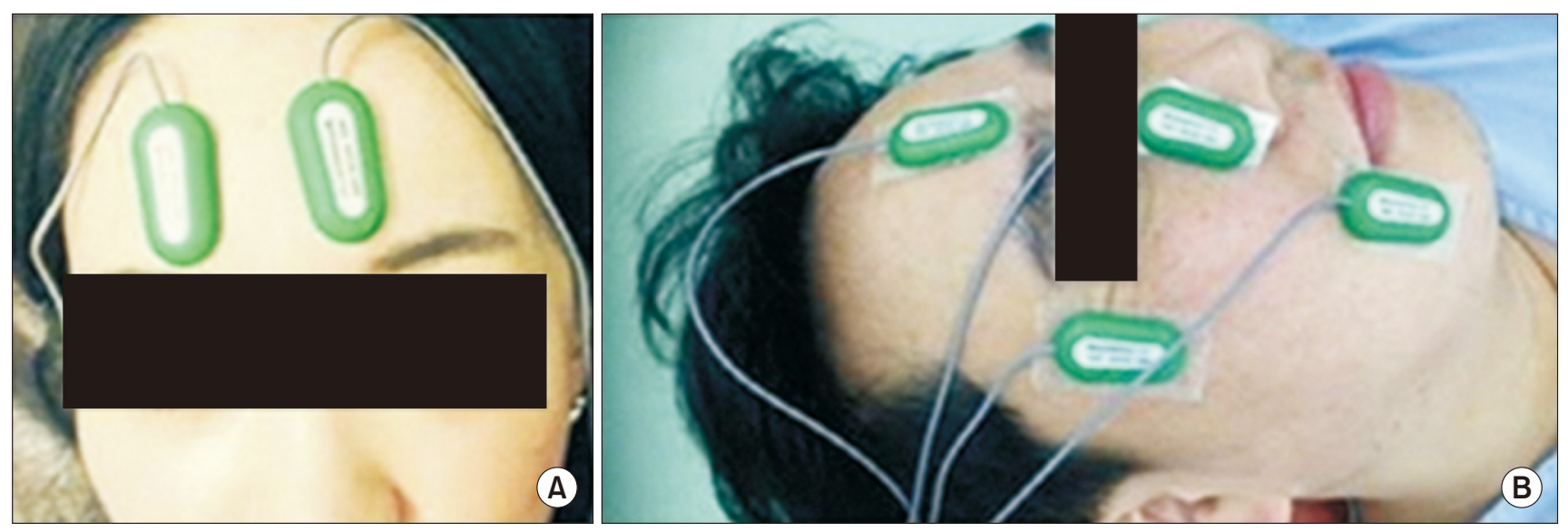

Fig. 1. Electrode placement. (A) Symmetrically attached bipolar electrodes on the frontalis muscles. (B) Recording electrodes' positions on the right side of the face. (From left to right, in turn, frontalis, orbicularis oculi, nasalis, and orbicularis oris).

placed over the truncal region of the facial nerve on the skin over the stylomastoid foramen and manually adjusted to determine the best position to generate the CMAP. The recording electrodes were placed on the surface of the target muscle (the frontalis, orbicularis oculi, nasalis, and orbicularis oris muscle). The ground electrode was placed around the patient's chin. Rectangular pulses 0.1 millisecond long with a frequency of $1 \mathrm{~Hz}$ were produced. The intensity of stimulation was increased stepwise until there was no further increase in the amplitude of the diphasic myogenic CMAP. The stimulation intensity ranged from 20 to $40 \mathrm{~mA}$.

\section{5) Surface EMG evaluation}

The patients with facial palsy confirmed by conventional electrodiagnostic studies were examined by SEMG immediately after the conventional study. SEMG of the same facial muscles (the frontalis, orbicularis oculi, nasalis, and orbicularis oris muscles) were recorded from bilaterally applied small surface electrodes. The electrode sites were rubbed with an alcohol wipe to minimize the impedance of the skin. ${ }^{18}$ After skin preparation, the surface electrodes, which were coated with electrode gel, were attached to the skin with flexible adhesive tape. The electrodes were attached to the same site in all patients. After the pairs of SEMG electrodes were placed over the skin each patient was instructed to remain quiet and relaxed for 1 minute. Each participant was asked to activate their muscles for 5 seconds and then relax for 5 seconds (As in previous study, the frontalis; raises eyebrows, the orbicularis oculi; closes eyes, the nasalis; compress the nasal cartilages, the orbicularis oris; pucker the lips, all muscles contraction was instructed to do as much as possible). ${ }^{19}$ This test was carried out three consecutive times.

During the test, there was a difference in the electromyography signals due to lack of understanding of how to make a facial expression or because of muscle fatigue. The largest of the three measurements considered as maximal voluntary contraction (MVC) and reflected in the results to check the correlation with a conventional EMG that applies supramaximal stimulation. During the MVC, the SEMG amplitude as assessed by peak RMS values was obtained from the nonsmoothed SEMG periodograms.

We next calculated the amplitude loss ratio of the RMS values obtained by SEMG compared to the unaffected side (RSEMG) and the amplitude loss ratio of CMAP amplitudes compared to the unaffected side (RCMAP). The ratio of amplitude loss was calculated as 1-[amplitude on affected side / amplitude on healthy side]. 


\section{6) Pain score \& test time evaluation}

We also measured pain score and the time required to run the test. The pain score was measured with the visual analogue scale (VAS). A digital watch was used to measure test time, in seconds.

\section{7) Data analysis}

SEMG traces were evaluated for onset, peak, and offset of activity during muscle activation. Onset was identified as the point of upward excursion of the SEMG trace from baseline (rest) that led into the muscle activation. Peak was the highest amplitude of the SEMG. Offset was the point at which SEMG activity returned to baseline. The raw SEMG is the signal that is actually generated by the muscle. Fig. 2 shows a raw SEMG signal. In the raw graph, the $\mathrm{X}$ axis displays time and the $\mathrm{Y}$ axis displays amplitude in $\mu \mathrm{V}$ (microVolts), both positive and negative, about the axis which centers on zero. The RMS, also known as the quadratic mean, is defined as the square root of the arithmetic mean of the squares of a set of numbers. ${ }^{20}$

$$
x_{\mathrm{rms}}=\sqrt{\frac{1}{n}\left(x_{1}^{2}+x_{2}^{2}+\cdots+x_{n}^{2}\right)} .
$$

Computer software was used to calculate the RMS values of the action potentials during muscle movements. Then, we calculated the RSEMG and RCMAP.

\section{8) Statistical analysis}

The relationship between the RSEMG and RCMAP was studied by the Pearson product-moment correlation coefficient (P-correlation coefficient) after applying linear regression to the data and the relationship between HB grade and RSEMG was analysed by the Spearman correlation coefficient.

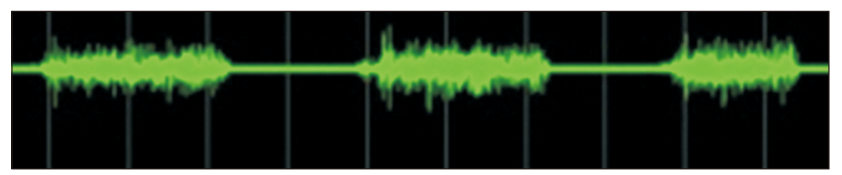

Fig. 2. Surface EMG periodogram.
The level of significance was set at $p<0.05$. The SPSS 17.0 statistical analysis program was used for statistical analyses.

\section{Results}

\section{1) Clinical characteristics}

A total of thirty six patients were enrolled in this study. Their palsies were scored as HB Grade II (18 patients), III (10), IV (7), and V (1). The subjects' mean age was $48.7 \pm 14.5$ years. Patient demographics and clinical characteristics are given in Table 1.

\section{2) Correlation of parameters}

The values of RSEMG and RCMAP are given in Table 2. Our findings demonstrated a correlation between the RMS values of the SEMG and electrodiagnostic severity according to the amplitudes of CMAP in patients with facial nerve palsy (Fig. 3). There was a statistically significant correlation between RSEMG and RCMAP in the facial muscles (frontalis, oculi, nasalis, oris) $(p<0.05$ ). The largest correlation coefficient was found in the frontalis $(r=0.567)$ and the smallest correlation coefficient was found in the nasalis $(r=0.393)$. A correlation between HB scale and RSEMG was demonstrated

Table 1. Characteristics and Numbers of Patients

\begin{tabular}{lc}
\hline \hline & Total $(\mathrm{N}=36)$ \\
\hline Sex (numbers) & Male $=18$, Female $=18$ \\
Average age (years) & $48.17 \pm 17.56$ \\
House-Brackmann grade & $2.75 \pm 0.87$ \\
& $(\mathrm{II}=18, \mathrm{II}=10, \mathrm{IV}=7, \mathrm{~V}=1)$ \\
Elapsed time (days) & $46.67 \pm 53.73$ \\
Involved side & Right $=18$, Left $=18$ \\
\hline
\end{tabular}

Data are presented as mean \pm standard deviation

Table 2. RSEMG and RCMAP Values

\begin{tabular}{lcc}
\hline \hline & RSEMG & RCMAP \\
\hline Frontalis & $0.69 \pm 0.24$ & $0.65 \pm 0.28$ \\
Orbicularis oculi & $0.71 \pm 0.25$ & $0.66 \pm 0.24$ \\
Nasalis & $0.67 \pm 0.21$ & $0.68 \pm 0.25$ \\
Orbicularis oris & $0.71 \pm 0.19$ & $0.75 \pm 0.24$ \\
\hline
\end{tabular}

Data are presented as mean \pm standard deviation RSEMG: the amplitude loss ratio of the value of the RMS values, RCMAP: the amplitude loss ratio of the CMAP 

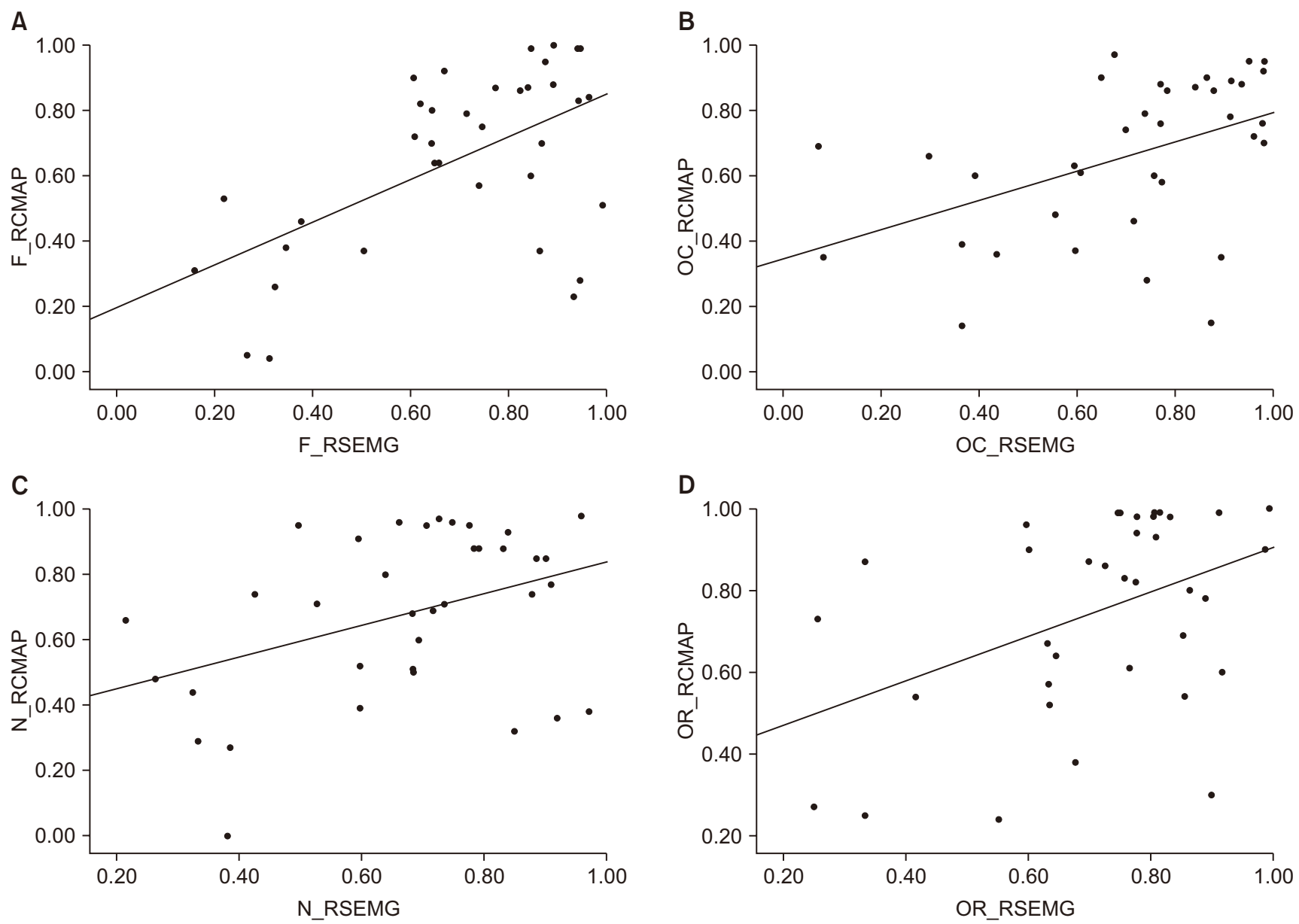

Fig. 3. Correlation between RSEMG and RCMAP in the facial muscles. (A) F_RSEMG: the amplitude loss ratio of the frontalis RMS values, F_RCMAP: the amplitude loss ratio of the CMAP of the frontalis $(r=.567, p<0.01)$. (B) OC_RSEMG: the amplitude loss ratio of the orbicularis oculi RMS values, OC_RCMAP: the amplitude loss ratio of the CMAP of the orbicularis oculi $(r=.465, p<0.01)$. (C) N_RSEMG: the amplitude loss ratio of the nasalis RMS values, N_RCMAP: the amplitude loss ratio of the CMAP of the nasalis $(r=.393, p<0.02)$. (D) OR_RSEMG: the amplitude loss ratio of the orbicularis oris RMS values, OR_RCMAP: the amplitude loss ratio of the CMAP of the orbicularis oris $(r=.437, p<0.01)$.

(Table 3). According to the results of our analyses, the HB scale score and RSEMG were meaningfully related in four facial muscles.

\section{3) Pain score and test time}

During the SEMG and conventional EMG test, we recorded the severity of subjective patient pain and examination time. The VAS score, which indicates pain experienced during the test, showed significant improvement using the SEMG method. The mean VAS score with conventional EMG was $3.55 \pm 1.42$, whereas that experienced when using SEMG was $0.11 \pm 0.52$. Test time was significantly reduced using SEMG. The mean time required for conventional EMG was $610 \pm$
Table 3. Correlation between House-Brackmann Grade and RSEMG

\begin{tabular}{lcccc}
\hline \hline & F_RSEMG & OC_RSEMG & N_RSEMG & OR_RSEMG \\
\hline $\begin{array}{c}\text { Spearman } \\
\text { correlation } \\
\text { coefficient } \\
\text { p-value }\end{array}$ & 0.482 & 0.685 & 0.341 & 0.630 \\
\hline
\end{tabular}

F_RSEMG: the amplitude loss ratio of the frontalis RMS values, OC_ RSEMG: the amplitude loss ratio of the orbicularis oculi RMS values, N_RSEMG: the amplitude loss ratio of the nasalis RMS values, OR_ RSEMG: the amplitude loss ratio of the orbicularis oris RMS values ${ }^{*} p<0.05$

103.84 seconds, while that required for SEMG was 420 \pm 86.32 seconds. 


\section{Discussion}

SEMG has been used for both research and clinical applications. Muscle activation intervals are useful in evaluating motor coordination and treatment efficacy, ${ }^{9}$ and myoelectrical manifestations of fatigue ${ }^{7,10}$ can be used to assess EMG signal modifications in patients with pathologies such as back pain, ${ }^{11-13}$ neurological diseases ${ }^{14}$ and exercise-related pain. ${ }^{15,16}$ Recently, there have been an increasing numbers of studies that used SEMG to measure facial muscle activity. Schumann et al. studied the activation pattern of facial muscles during facial movement using SEMG, ${ }^{17}$ and Castroflorio et al. investigated masticatory muscle activity in patients with temporomandibular disorders. ${ }^{21}$

In this study, a considerable correlation was shown between the results of RSEMG and RCMAP. In addition, HB grade was significantly correlated with RSEMG values. Kim et al. investigated the correlation between SEMG and clinical parameters in facial palsy patients, and reported that there was a significant correlation, which is in agreement with the results of the current study. ${ }^{19}$ The greatest correlation was shown in the frontalis muscle $(r=0.567, p<0.01)$, while the lowest correlation was found in the nasalis muscle ( $\mathrm{r}=$ 0.393, $\mathrm{p}<0.02$ ). The frontalis muscles are bigger than other facial muscles and independently located. Their anatomic position may reduce the influence of nearby muscles during muscular contraction. On the contrary, the nasalis is small and coexists with other small muscles nearby (the levator labii, zygomaticus, oris, and oculi), so the action of other muscles during muscular contraction would logically affect the measurement results.

In many studies, efforts have been made to research EMG-related pain and to reduce such pain. Patients suffer from severe pain during electromyography, which tends to lower patient compliance. ${ }^{22-24}$ Dikmen et al. investigated VAS scores during NCS, and found a mean score of $3.60 \pm 2.52$ (mean VAS \pm SD). ${ }^{25}$ The current study found a mean VAS score of $3.55 \pm 1.42$, which is similar to the previous study. However, SEMG resulted in a mean VAS score of only $0.11 \pm 0.52$, which indicates that patients were in much less pain during that procedure.

This study has several limitations. First, skin impedance has a significant effect on the amplitude of the measured EMG signal. The consistency of impedance between electrode and skin sites is critical for the reliability of EMG measurements. ${ }^{18}$ The impedance at each site does not have to be perfectly unchanged, but it should be relatively unchanged in order to be able to compare measurements taken at different sites. Therefore, this study could use not absolute value measurements but instead compared the ratio of the measurements taken from the normal and abnormal sides. So, it may be that there was little impact from external change. Second, the number of enrolled patients with severe symptoms (House-Brackmann grades 4 or 5) was smaller than that of patients with mild symptoms (House-Brackmann grades 2 or 3), so the results may not fully apply to patients with more severe systems. Third, the timing of the study varied, as each patient was referred to our rehabilitation center at a different time. Fourth, SEMG results may be different depending on the degree of volition of the patient and more sensitive to the effects of surrounding muscles than conventional EMG. In patients with facial palsy, electromyography is often used to predict prognosis rather than diagnosis. We conclude that SEMG is less invasive than conventional EMG in diagnosis, however we could not confirm the prognosis, and further study will be needed on this.

In summary, this study shows that SEMG results are meaningfully correlated with both conventional EMG results and disease severity as assessed by a clinical scale (HB). We also found that patients experienced less pain during the SEMG test than during the conventional test. We propose that SEMG can be used to diagnose facial palsy because it is more comfortable and faster than conventional methods. 


\section{References}

1. Yanagihara N: Incidence of Bell's palsy. Ann Otol Rhinol Laryngol Suppl 1988: 137: 3-4

2. Truelsen T, Piechowski-Jozwiak B, Bonita R, Mathers C, Bogousslavsky J, Boysen G: Stroke incidence and prevalence in Europe: a review of available data. Eur J Neurol 2006: 13: 581-598

3. Heuschmann PU, Di Carlo A, Bejot Y, Rastenyte D, Ryglewicz D, Sarti C, et al.: Incidence of stroke in Europe at the beginning of the 21st century. Stroke 2009: 40: 1557-1563

4. Rosler KM, Hess CW, Schmid UD: Investigation of facial motor pathways by electrical and magnetic stimulation: sites and mechanisms of excitation. J Neurol Neurosurg Psychiatry 1989: 52: 1149-1156

5. Ghonim MR, Gavilan C: Blink reflex: prognostic value in acute peripheral facial palsy. ORL J Otorhinolaryngol Relat Spec 1990: 52: 75-79

6. Dumitru D, Amato A, Zwarts M: Electrodiagnostic medicine, 2nd ed, Philadelphia: Hanley\& Belfus Inc., 2002, pp678-679

7. De Luca CJ: The use of surface electromyography in biomechanics. Journal of applied biomechanics 1997: 13: 135-163

8. Merletti R, Rainoldi A, Farina D: Surface electromyography for noninvasive characterization of muscle. Exerc Sport Sci Rev 2001: 29: 20-25

9. Sutherland DH: The evolution of clinical gait analysis part 1: kinesiological EMG. Gait Posture 2001: 14: 61-70

10. Merletti R, Knaflitz M, De Luca CJ: Myoelectric manifestations of fatigue in voluntary and electrically elicited contractions. J Appl Physiol (1985) 1990: 69: 1810-1820

11. Hodges PW, Richardson CA: Feedforward contraction of transversus abdominis is not influenced by the direction of arm movement. Exp Brain Res 1997: 114: 362-370

12. Mannion AF, Dumas GA, Stevenson JM, Cooper RG: The influence of muscle fiber size and type distribution on electromyographic measures of back muscle fatigability. Spine (Phila Pa 1976) 1998: 23: 576-584

13. Han JY, Ju SR, Choi IS, Lee SY, Lee SG, Rowe SM: The Assessment of Chronic Low Back Pain by Surface Electromyography. J Korean Acad Rehabil Med 2002: 26: 739-744

14. Zwarts MJ, Drost G, Stegeman DF: Recent progress in the diagnostic use of surface EMG for neurological diseases. J Electromyogr Kinesiol 2000: 10: 287-291
15. Casale R, Rainoldi A, Nilsson J, Bellotti P: Can continuous physical training counteract aging effect on myoelectric fatigue? A surface electromyography study application. Arch Phys Med Rehabil 2003: 84: 513-517

16. Lee HS, Shim JS, Lee ST, Kim M, Ryu JS: Facilitating effects of fast and slope walking on paraspinal muscles. Ann Rehabil Med 2014: 38: 514-522

17. Schumann NP, Bongers K, Guntinas-Lichius O, Scholle HC: Facial muscle activation patterns in healthy male humans: a multi-channel surface EMG study. J Neurosci Methods 2010: 187: $120-128$

18. Lindsey KT, Rohan KJ, Roecklein KA, Mahon JN: Surface facial electromyography, skin conductance, and self-reported emotional responses to light- and season-relevant stimuli in seasonal affective disorder. J Affect Disord 2011: 133: 311319

19. Kim JU, Lee HG, Jung DJ, Choi YM, Song BY, Yook TH, et al.: A study on the correlation between surface electromyography and assessment scale for facial palsy. The Acupuncture 2013: 30: 107-116

20. Gant L, Fethke N, Gerr F: Spectral analysis of root-meansquare processed surface electromyography data as a measure of repetitive muscular exertion. Proceedings of the $\mathrm{Hu}-$ man Factors and Ergonomics Society Annual Meeting; 2012 October 22-26 USA. Boston: SAGE Publications; 2012

21. Castroflorio T, Talpone F, Deregibus A, Piancino MG, Bracco $\mathrm{P}$ : Effects of a functional appliance on masticatory muscles of young adults suffering from muscle-related temporomandibular disorders. J Oral Rehabil 2004: 31: 524-529

22. Walker WC, Keyser-Marcus LA, Johns JS, Seel RT: Relation of electromyography-induced pain to type of recording electrodes. Muscle Nerve 2001: 24: 417-420

23. Yalinay Dikmen P, Ilgaz Aydinlar E, Karlikaya G: Pain levels of examined muscles and gender differences in pain during electromyography. Agri 2015: 27: 79-82

24. Kalantar SS, Abbasi M, Faghihi-Kashani S, Majedi H, Ahmadi M, Agah E, et al.: Paracetamol 325 mg/tramadol $37.5 \mathrm{mg}$ effect on pain during needle electromyography: a doubleblind crossover clinical trial. Acta Neurol Belg 2016: 116: 599-604

25. DİKMEN PY, Aydinlar EI, Karlikaya G: Expected and experienced pain levels in electromyography. Noro Psikiyatr Ars 2013: 50: 364-367 